\title{
A RANDOMISED CONTROL STUDY TO COMPARE THE EFFICACY OF CEFUROXIME, CLARITHROMYCIN, AND LEVOFLOXACIN IN THE MANAGEMENT OF PAEDIATRIC UPPER RESPIRATORY TRACT INFECTION
}

\author{
GOUTHAMI PADUGUNDLA ${ }^{1}$, JYOTHIRMAYEE $\mathrm{V}^{2 *}$, BETHALA RAVALI ${ }^{2}$, JAGILLAPURAM ARUNDHATHI², \\ THAKUR SRILATHA ${ }^{2}$, NOORBASHA NISSI ${ }^{2}$, ARSHIYA ANJUM ${ }^{2}$
}

${ }^{1}$ Department of Pediatrics, RVM Institute of Medical Sciences, Hyderabad, Telengana, India. ${ }^{2}$ Department of Pharmacy Practice Geethanjali College of Pharmacy, Medchal, Telangana, India. Email: jyothivattem@gmail.com

Received: 30 July 2021, Revised and Accepted: 10 September 2021

\section{ABSTARCT}

Objective: The upper respiratory infections cause considerable morbidity mainly in children due to the fact that they mainly affect children. Accordingly, a study was conducted on antibiotics to compare the effectiveness of clarithromycin, cefuroxime, and levofloxacin for treating upper respiratory tract infections (URTI) in children.

\begin{abstract}
Methods: A prospective observational study for a period of 6 months was conducted in the pediatrics department of RVM hospital. Outpatients under the age of 14 years given antibiotics for the treatment of URTI were included in the study. A total of 99 study subjects were included in the study, divided into three groups each containing 33 sample sizes (clarithromycin, cefuroxime, and levofloxacin). Patient data was collected using a form and verbal consent was obtained from patients/patient representatives, and drugs were given using the lottery method. Follow-up was done and noted for the $3^{\text {rd }}, 5^{\text {th }}, 7^{\text {th }}$ day through telephonic calls, and the collected data were evaluated using statistical analysis.
\end{abstract}

Results: Pool data from 99 patients shows that many patients belong to 0-5 years age groups (age distribution), and males were more than female (gender distribution). Clarithromycin (cure rate 3 days) and cefuroxime (cure rate 5 days) showed an equal rate of cure percentage (94\%), while levofloxacin for 3-5 days with a 3\% failure rate. A significant difference of $\mathrm{p}<0.05(\mathrm{p}=0.000)$ was observed and no adverse events were noted.

Conclusion: The study findings showed, out of 3 drugs, clarithromycin and cefuroxime showed an equal efficacy rate of $94 \%$, but clarithromycin showed shorter duration of outcome, i.e., 3 days. Hence, clarithromycin is effective than the other two drugs in the treatment of URTI.

Keywords: Upper respiratory tract infections, Clarithromycin, Cefuroxime, Levofloxacin, Pediatrics.

(c) 2021 The Authors. Published by Innovare Academic Sciences Pvt Ltd. This is an open access article under the CC BY license (http://creativecommons.org/ licenses/by/4.0/) DOI: http://dx.doi.org/10.22159/ajpcr.2021v14i10.42957. Journal homepage: https://innovareacademics.in/journals/index.php/ajpcr

\section{INTRODUCTION}

The respiratory tract is much more vulnerable to infection than other body parts since bacteria or viruses can easily enter the tract when a person breathes in [1]. The upper respiratory tract infections (URTI) include epiglottis, otitis media, laryngitis, pharyngitis, acute rhinitis, laryngotracheitis, influenza, tonsillitis, and acute rhinosinusitis [2].

URTI is a frequent major morbid condition among pediatrics. Acute pharyngitis constitutes 1 percent of all admissions to the outpatient hospital, and predominantly seen in 4-7-year-old patients [3]. The incidence of epiglottis has significantly decreased. Pertussis has an estimated occurrence of 48.5 million cases worldwide and causes about 295,000 deaths per annum. In low-income countries, the infant mortality rate is found at about $4 \%$. The increased level may affect children in more percentages, but hormonal effects may also affect nasal mucosa [4].

Majority of hospital visits in children are caused by infection, therefore, children are prescribed a variety of antibiotics. One of the reasons children are particularly vulnerable to respiratory infections is that they breathe more rapidly than adults and so absorb more pollutants. Physicians are frequently challenged by antimicrobial resistance (AMR) associated with community-acquired respiratory tract infections. According to the World Health Organization (WHO), 600,000 children died in 2016 from acute lower respiratory infections caused by polluted air. The rate of occurrence of adverse drug reaction (ADR) is also very high in pediatrics compared to adults. Approximately 58,000 infants died in 2013 in India due to antibiotics failing to save them from infections $[5,6]$.
Antibiotics are of the commonly prescribed drugs in hospitals, particularly in pediatric wards. AMR results from widespread irrational use of antimicrobials, despite the emergence and extraordinary advances in medical technology. AMR results from altered susceptibility in organisms due to their widespread irrational use. Recent years have seen a surge in incidents of AMR, and they are receiving global attention. In spite of the fact that AMR is a result of many factors, one of the most significant causes is antibiotic indiscrimination. Infections were the most common clinical approach, making India one of the most leading consumers of antimicrobials in the world [7].

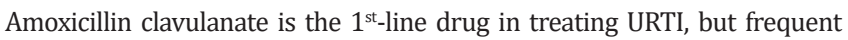
use of any antibiotic leads the way to resistance and failure of treatment [8]. Hence, in this period of increasing AMR, it is essential to have an efficient and safe alternative drug along with first-line agents. With a quest to select a better alternative, we took antibiotics from each major class of antibiotics, i.e., cefuroxime from cephalosporins, clarithromycin from macrolides, and levofloxacin from fluoroquinolones. The current study is designed to elicit and correlate the effects of cefuroxime, clarithromycin, and levofloxacin.

\section{METHODS}

Study site and duration

The investigation was done in pediatrics outpatient care of 800 bedded RVM institutes of medical sciences and research center, a tertiary care hospital located in Lakshmakkapally, Medak District, Telangana. The study duration was 6 months between October 2020 and March 2020. 


\section{Study design}

A prospective, interventional, randomized double-blind, observational study was conducted among subjects with URTI attending the outpatient pediatric department of RVM hospital. The three antibiotics (cefuroxime, clarithromycin, and levofloxacin) commonly prescribed for URTI were assessed and compared for their therapeutic efficacy. The strength doses $(15 \mathrm{mg} / \mathrm{kg} / 7$ days $)$ and duration of treatment of the three antibiotics were given as per the WHO model formulary for children and Model List of Essential Medicines 2019 to ensure that given drug in prescribed dose is safe in children $[9,10]$.

A. Clarithromycin syrup - CLARINOVA - $125 \mathrm{mg} / 5 \mathrm{ml}$

B. Cefuroxime syrup - CEFAKIND $-125 \mathrm{mg} / 5 \mathrm{ml}$

C. Levofloxacin syrup - L-CIN $-125 \mathrm{mg} / 5 \mathrm{ml}$.

The physician was kept unaware of the codes given to each antibiotic to ensure blinding. When a subject meets inclusion criteria approaches the outpatient department, the prescriber selected a chit written with the code A, B, or C by lottery method. The pharmacist was requested to dispense antibiotics as mentioned above upon receiving the study prescriptions. The study was initially approved by the institutional ethical committee (code: GCPK/IEC/JUNE2019-20/B04) and consent was obtained from the study subjects (parents/guardians) before the study. They were explained about the telephonic follow-up before the study (Fig. 1).

\section{Inclusion and exclusion criteria}

Outpatients $\leq 14$ years with diagnosed with URTI in the pediatric department of RVM hospital were included in the study. Patients other than URTI, >14 years and inpatients of pediatric department of RVM hospital were excluded from the study.

\section{Sample size and data collection}

A total of 99 sample size was collected having 33 samples in each category of antibiotics. Before including in the study, a written informed was taken from study subjects. During the 6 months of study, relevant information was collected from the patient representative, by asking questionnaires including chief complaints, past/present medication history, etc., and entered into pre-designed data collection forms. Follow-up regarding alleviation of symptoms, ADR, if any, and adherence was done through telephonic interview starting at $3^{\text {rd }}$ day followed by $5^{\text {th }}$ and $7^{\text {th }}$ day based on necessity and till symptoms subside.

\section{Classification of outcomes}

The outcomes of the study subjects were classified as:

Cured

If, patient is completely relieved from symptoms by the treatment.

Improved

If, the patient's condition is better than before by the treatment.

\section{Failed}

If, the patient's situation is deteriorated or no betterment is observed by the treatment.

\section{Statistical analysis}

Descriptive statistics and graphical presentation of data analysis were shown as frequency, percentage, mean, and SD. Comparisons of categorical data between groups were done using Pearson $\chi^{2}$ analysis, Kruskal Wallis Test, and 1-way analysis of variance (ANOVA). Statistical analysis, using SPSS statistical software, version 22, was performed.

\section{RESULTS}

Out of 99 patients, the patient's near age was noticed to be $4.92 \pm 3.65$ years with average weight of $13.9 \pm 12.0 \mathrm{~kg}$. Most patients fall under the peer group of $0-5$ years (68\%). Out of 99 patients, 52 are male and 47 are female (Table 1 ).
On the telephonic interview, the treatment outcomes were observed and the effects of three drugs were compared. A $\chi^{2}$-test was applied to check the homogeneity of the attributes in respect of a particular characteristic. The results showed that clarithromycin and cefuroxime appeared effective than levofloxacin. Among 33 subjects received levofloxacin, $52 \%$ of subjects reported complete cure, $45 \%$ improved their clinical symptoms, while $3 \%$ reported no improvement upon antibiotic treatment (Table 2 and Fig. 2).

The findings of duration of treatment outcomes showed that majority of subjects receiving clarithromycin (73\%) showed improvement in their symptoms within three days while it was 5 days for cefuroxime $(73 \%)$ and 7 days for levofloxacin (58\%). One way ANOVA is performed to correlate the effects of the drugs by the period of outcome, i.e., 3 days $/ 5$ days/ 7 days (parametric) and was found that clarithromycin has shown more efficacy within less duration i.e., 3 days (Table 3 and Fig. 3).

\section{DISCUSSION}

Among 99 pediatric study subjects, the prevalence of URTI is high in 0-5 year's age group may be due to low immunity. On the telephonic follow-up of patients, we checked on the compliance of subjects and established that patients in all drug groups were adherent to every medication prescribed to them. So failure to receive medication was not a factor for the efficacy shown by the test drugs. No ADR was reported

Table 1: Age, gender, and body weight-wise distribution of the study population

\begin{tabular}{lllll}
\hline Parameter & \multicolumn{2}{l}{ Frequency (n=99) } & \multirow{2}{*}{ Total (\%) } \\
\cline { 2 - 4 } & Drug A & Drug B & Drug C & \\
\hline Age & & & & \\
0-5 years & 27 & 24 & 16 & $67(68)$ \\
6-10 years & 3 & 7 & 12 & $22(22)$ \\
11-14 years & 3 & 2 & 5 & $10(10)$ \\
Total & 33 & 33 & 33 & \\
$\quad$ Mean \pm SD & $3.7 \pm 3.5$ & $4.7 \pm 3.1$ & $6.3 \pm 3.8$ & $4.92 \pm 3.65$ \\
$\quad$ IQR & $0.2-13$ & $0.2-14$ & $0.6-13$ & \\
Gender & & & & \\
$\quad$ Male & 19 & 15 & 18 & $52(53)$ \\
Female & 14 & 18 & 15 & $47(47)$ \\
Average weight & $10.9 \pm 10.1$ & $15.1 \pm 13.9$ & $12.5 \pm 10.9$ & $13.9 \pm 12.0$ \\
\hline
\end{tabular}

Table 2: Comparison of treatment outcomes of three antibiotics given for URTI in paediatrics

\begin{tabular}{lllll}
\hline Drugs & \multicolumn{2}{l}{ Outcome } & & $\left(\boldsymbol{\chi}^{2}, \mathbf{p}<\mathbf{0 . 0 5}\right)$ \\
\cline { 2 - 4 } & Cured & Improved & Failure & \\
\hline Drug A & $31(94)$ & $2(6)$ & 0 & $\left(22.43,0.0000^{*}\right)$ \\
Drug B & $31(94)$ & $2(6)$ & 0 & \\
Drug C & $17(52)$ & $15(45)$ & $1(3)$ & \\
Total & 79 & 19 & 1 & \\
\hline
\end{tabular}

${ }^{*} \mathrm{p}<0.05$ is a significant relation $\mathrm{b} / \mathrm{w}$ Drugs and Outcome by using $\chi^{2}$-test, URTI: Upper respiratory tract infections

Table 3: Comparison of duration of treatment outcomes of three antibiotics given for URTI in paediatrics

\begin{tabular}{llllll}
\hline \multirow{2}{*}{ Drugs } & \multicolumn{3}{l}{ Duration of outcome in days n (\%) } & \multirow{2}{*}{ (F, p<0.05) } \\
\cline { 2 - 5 } & 3 Days & 5 Days & 7 Days & Mean \pm SD & \\
\hline Drug A & $24(73)$ & $6(18)$ & $3(9)$ & $3.73 \pm 1.31$ & $(24.87,0.0000)$ \\
Drug B & $7(21)$ & $24(73)$ & $2(6)$ & $4.70 \pm 1.02^{*}$ & \\
Drug C & $4(12)$ & $10(30)$ & $19(58)$ & $5.91 \pm 1.42^{*}$ & \\
Total & 35 & 40 & 24 & & \\
\hline
\end{tabular}

$* \mathrm{p}<0.05$; Duration of Outcome mean values are statistically noticeable between drugs by using one-way ANOVA, URTI: Upper respiratory tract infections 


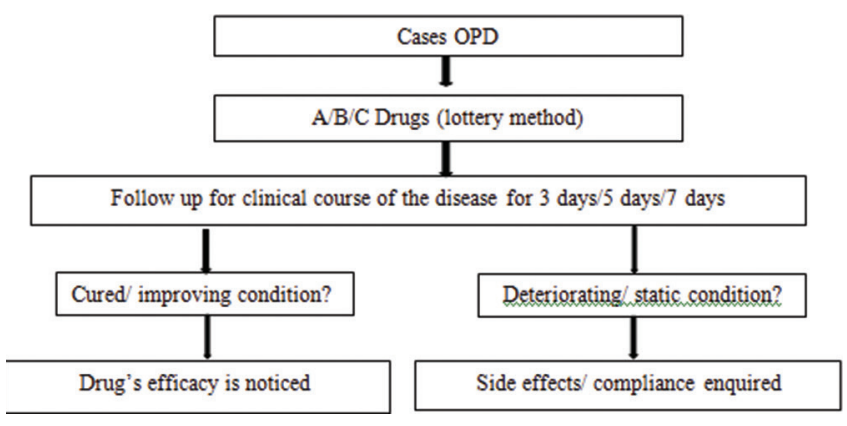

Fig. 1: Study design flow chart

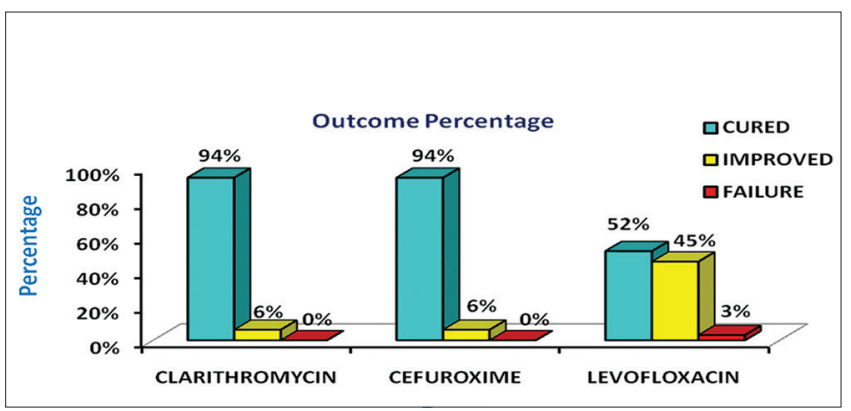

Fig. 2: Comparison of treatment outcomes of three antibiotics given for Upper respiratory tract infections in paediatrics

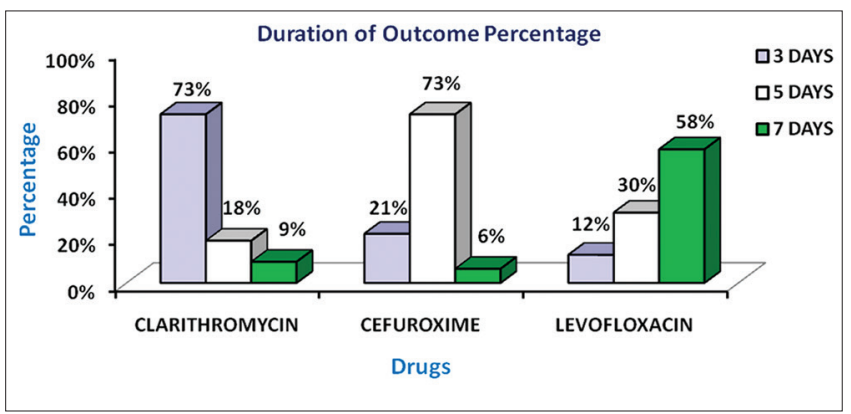

Fig. 3: Comparison of duration of treatment outcomes of three antibiotics given for Upper respiratory tract infections in paediatrics

by the patient's caregivers upon telephonic inquiry. However, it does not mean that there won't be any ADR with the test drugs.

Among the clarithromycin, cefuroxime and levofloxacin groups, clarithromycin and cefuroxime have shown a $94 \%$ cure rate whereas levofloxacin showed $52 \%$ cure rate. Collating with the study conducted by Siepman in the year, 1998, it was found that these 2 drugs were equally efficacious [11]. A study by Guay et al., expressed that clarithromycin has high effects than cefuroxime. Another study by Henry concluded that cefuroxime ( $250 \mathrm{mg}$, twice daily) is as potent as amoxicillin (500 mg, TID) that provide baseline data for the utility of these selected antibiotics in URTI $[11,12]$.

A study by AdelGlass et al., in contrast to the above results, concluded that levofloxacin and clarithromycin showed equal efficacy but the standards of life for levofloxacin are higher [13]. In a randomized comparative study of levofloxacin versus amoxicillin/clavulanate for treatment of pediatrics reported cure rates of $72.4 \%$ in levofloxacin-treated and $69.9 \%$ (472 of 675 ) in amoxicillin/clavulanate-treated children [14]. In a similar study of comparison of the efficacy of clarithromycin, levofloxacin, and cefuroxime among adults infected with bronchitis reported, clinical cure rate of $87.9 \%$ with clarithromycin, $87.4 \%$ with levofloxacin, and $79.8 \%$ of those treated with cefuroxime [15].

In this study, the failure with the medication was seen in the Levofloxacin group only (3\%). This may be because of variability between subjects and various factors that could not be studied here. Clarithromycin has shown cure before completing three days in $73 \%$ of individuals whereas cefuroxime has shown $73 \%$ within 5 days. Moreover, $50 \%$ of them were healed between 3 and 5 days of treatment. The time of treatment is longer in the levofloxacin group, most patients took more than 5 days for improvement in symptoms.

Antibiotic resistance has made infections more difficult to treat today, leading to life-threatening situations. Despite this, there are numerous encouraging research opportunities in antibiotic use, particularly in children. In the global context, antibiotic usage, awareness, knowledge, and practice need to be understood. As reported by the WHO, India is among the countries with a high rate of drug resistance coupled with the irrational use of antimicrobial agents. Despite developing research on antimicrobial stewardship, the country is primarily interested in drug discovery and development $[16,17]$.

\section{CONCLUSION}

By considering our study conducted on 99 patients, we conclude that all three drugs are not equally efficacious in treating URTI in pediatric patients. Amidst three antibiotics, clarithromycin is more preferable. The study can be repeated in a larger sample size to increase reliability. As our study is conducted with limited resources, the study can be strengthened by culture sensitivity data and patient compliance was $100 \%$ and no side effects were observed. However, it cannot be extrapolated to the bigger sample or population. So advance research in some more populations can be held to know safety with these antibiotics in pediatric population.

\section{ACKNOWLEDGMENTS}

The investigators extend gratitude to RVM institutes of medical sciences and research center, for permitting to conduct the present study.

\section{CONFLICTS OF INTEREST}

The authors confirm that this article content has no conflicts of interest.

\section{FUNDING}

Not applicable.

\section{AUTHORS CONTRIBUTION}

The authors have made considerable contributions to the work reported in the manuscript.

\section{REFERENCES}

1. Health A-Z; 2021. Available from: https://www.hse.ie/eng/health/ $\mathrm{az} / \mathrm{r} /$ respiratory-tract-infection/causes-of-RTI-infections.html. [Last accessed on 2021 Aug 20].

2. Middle East Journal of Family Medicine; 2018. Available from: http:// www.mejfm.com/journal/May2006/epidemiology.htm. [Last accessed on 2021 Aug 20].

3. Influenza. World Health Organization; 2019. Available from: https:// www.who.int/immunization/diseases/influenza/en. [Last accessed on 2021 Aug 20].

4. Emedicinehealthline: Medical Author; 2017. Available from: https:// www.emedicinehealth.com/epiglottitis/article_em.htm. [Last accessed on 2021 Aug 20].

5. Chadalavada V, Triveni P, Begum S, Pujitha S. Drug use evaluation in the pediatrics admitted with severe respiratory tract infections. J Global Pharma Technol 2020;12:13-21.

6. Harria G. Superbugs' Kill India's Babies and Pose an Overseas Threat, The New York Times; 2014. Available from: https://www.nytimes. 
com/2014/12/04/world/asia. [Last accessed on 2021 Aug 20].

7. Rajesh B, Walia K. Combating antimicrobial resistance in India: Technical challenges and opportunities. Indian J Med Res 2017:146:683- 7

8. Indian Council of Medical Research. Treatment Guidelines for Antimicrobial Use in Common Syndromes; 2017. Available from: https://www.icmr.nic.in/guidelines. [Last accessed on 2021 Aug 20].

9. World Health Organization. Model List of Essential Medicines; 2019. Available from: https://www.apps.who.int. [Last accessed on 2021 Aug 20].

10. World Health Organization. Collaborating Center for Drug Statistics Methodology; 2019. Available from: https://www.whocc.no/atc_ddd index. [Last accessed on 2021 Aug 20].

11. Guay D, Siepman N, Tanaka S, Devcich K, Craft J. Comparative safety and efficacy of clarithromycin and 3 oral cephalosporins in the treatment of outpatients with bacterial bronchitis due to Haemophilus influenzae. Drug Investig 2012;6:33-41.

12. Henry DC. Comparison of cefuroxime axetil and amoxicillin/ clavulanate in the treatment of acute bacterial sinusitis. Clin Ther
1999;21:1158-70.

13. Adelglass J, Jones TM, Ruoff G, Kahn JB, Wiesinger BA, Katie RiellyGauvin BS, et al. Multicenter, Investigator-Blinded, Randomized Comparison of Oral Levofloxacin and Oral Clarithromycin. 1998;12551263.

14. Noel GJ. A Randomized comparative study of levofloxacin versus amoxicillin/clavulanate for treatment of infants and young children with recurrent or persistent Acute OM. Pediatr Infect Dis J 2008;27:483-9.

15. Weiss LR. Open-label, randomized comparison of the efficacy and tolerability of clarithromycin, levofloxacin, and cefuroxime axetil in the treatment of adults with acute bacterial exacerbation of chronic bronchitis. Clin Ther 2002;24:1414-25.

16. World Health Organization Report on Surveillance of Antibiotic Consumption: 2016-2018 Early Implementation; 2020. Available from: https://www.who.int/medicines/areas/rational use/amu surveillance/ en. [Last assessed on 2019 Jun 06].

17. Balamurugan K. Vineela $\mathrm{CH}$, Manoharbabu S. A review on role of pharmacists: Antimicrobial stewardship and in the battle against antimicrobial resistance in India. J Pharm Sci Innov 2018;7:91-7. 